\title{
Investigation of the Formation of Layered Nanostructure of Vanadium Xerogel
}

\author{
M. S. Markametova, ${ }^{1}$ B. Mishra, ${ }^{2}$ A. O. Baikonurova, ${ }^{1}$ \\ S. B. Nurzhanova, ${ }^{1}$ and Y. V. Ermolaev ${ }^{1}$ \\ ${ }^{1}$ Kazakh National Technical University Named after K.I. Satpaev, 22 Satpaev Street, Almaty 050013, Kazakhstan \\ ${ }^{2}$ Metallurgical \& Materials Engineering, Colorado School of Mines, 1500 Illinois Street, Golden, CO 80401, USA \\ Correspondence should be addressed to B. Mishra; bmishra@mines.edu
}

Received 30 July 2014; Revised 14 November 2014; Accepted 14 November 2014; Published 24 December 2014

Academic Editor: Shiren Wang

Copyright (C) 2014 M. S. Markametova et al. This is an open access article distributed under the Creative Commons Attribution License, which permits unrestricted use, distribution, and reproduction in any medium, provided the original work is properly cited.

The paper presents the results of a study of vanadium xerogel synthesized by sol-gel method. It shows that, during the aging process in gel formation, a layered fibrous chain structure of $\mathrm{V}-\mathrm{O}$ occurs at the nanoscale. Highly anisotropic particles, similar in size to the "tapes" of vanadium oxide gel, were found on the surface of partially ordered layers. IR spectroscopic analyses of groups of V=O and of $\mathrm{V}-\mathrm{O}$ bonds suggest that the high degree of order in the films is related to the fact that one of the water molecules is found to be short in double bonded $\mathrm{V}=\mathrm{O}$. Consequently, the growth chains take place predominantly in the plane equivalent to $\mathrm{OH}$ groups. Most of the VO-H consist of twisted (spiral) vanadium oxygen layers and have the morphology of tubes, the ends of which are open. Owing to such morphology of $\mathrm{VO}-\mathrm{H}$, significant structural flexibility is observed, which distinguishes them not only from carbon, but also from most other nanotubes.

\section{Introduction}

The level of current research in the area of advanced nanomaterials is increasing not only by the evolution of new methods for their synthesis, but also by the accurate testing of their physicochemical properties. An important characteristic that determines the properties of nanomaterials is the structure of nanocrystalline phases. One of the primary means of structural investigation of nanomaterials for their composition and structural features of constituent phases is by the X-ray diffraction method [1].

Phase transition of metal-semiconductors in compounds of d-and f-metals, mainly oxides, has been intensively studied by the X-ray diffraction method over the past forty years due to many different possibilities of its practical application [2-4]. It is found that in vanadium-oxygen system there are, according to different sources, about twenty compounds, beginning with suboxide of $\mathrm{V}_{9} \mathrm{O}$ to higher oxide of $\mathrm{V}_{2} \mathrm{O}_{5}$. Some of them, in particular, $\mathrm{V}_{2} \mathrm{O}_{3}$ and $\mathrm{VO}_{2}$, show a pronounced phase transition in commercial devices.
Intercalation compounds based on a layered structure of vanadium hydrate of $\mathrm{V}_{2} \mathrm{O}_{5} \cdot n \mathrm{H}_{2} \mathrm{O}$ have found industrial applications in recent years in the production of unique composites. These compounds have remarkable flexibility, high strength, and thermal and corrosion resistance. Researchers are paying special attention to the study of physical and chemical properties and the practical use of superfine powders and films of nanomaterials obtained by the sol-gel method [4]. The relevance of this layered material is that it may find application in such areas as catalyst, membranes for sewage treatment, cathode materials of the current source, the switching devices, and antistatic coating.

\section{Experimental Procedure}

Vanadium-containing gel has been synthesized by sol-gel method using ammonia as the precursor template [5]. The synthesis was carried out as follows. Vanadium pentoxide powder is melted in a muffle furnace at a temperature of 
TABLE 1: X-ray diffraction of the gel dried in air for $5 \mathrm{~min}$.

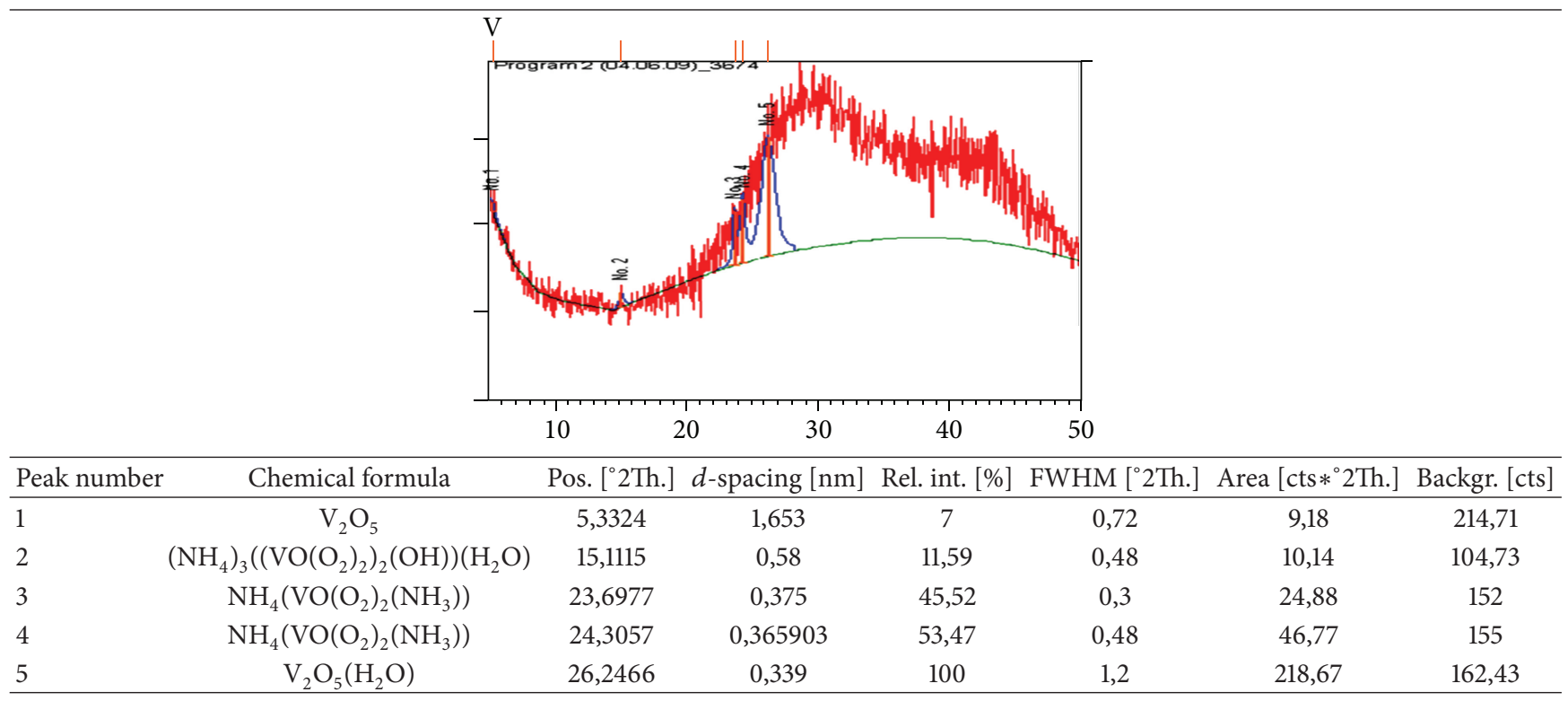

$670^{\circ} \mathrm{C}$. Next, melt is heated to a temperature of $850^{\circ} \mathrm{C}$ and this temperature is maintained for $30 \mathrm{~min}$. The material was then removed from the oven without precooling and is introduced into distilled water. The contents were stirred until complete dissolution of the solid. The resulting homogeneous brown solution turned out at a $\mathrm{V}_{2} \mathrm{O}_{5}$ concentration in the solution of approximately $25 \mathrm{~g} / \mathrm{L}$ and a $\mathrm{pH}$ value of 2.2 . Then, at a temperature of $\pm 22^{\circ} \mathrm{C}$ and constant stirring, a vanadium solution is added to a $30 \%$ ammonia solution. Upon reaching $\mathrm{pH}$ of 3.4, the solution was slowly solidified to form a sol with a vanadium compound with ammonia and then passed into solid gel by drying it in air at room temperature for 24 hours.

Synthesized gel has been examined by X-ray analysis. For this purpose the gel was predried in the air and was subjected to XRD analysis at intervals of five minutes. The analysis was performed on a diffractometer with high temperature attachment up to $1200^{\circ} \mathrm{C}$ in X'Pert MPD Pro (PANalytical) equipment using the detection of Bragg-Brendon tube mode under conditions of $30 \mathrm{KV}$ and $40 \mathrm{MA}$.

Microscopic analysis was performed with a scanning probe microscope with an attachment of Tape Integra Prima. Micrographs have been taken in the atomic force mode. Thermogravimetric studies have been conducted on the DTA/DSC NETZSCH STA 409 PC/PG system.

IR analysis of samples of vanadium-containing gel was performed on FT-IR spectrometer "Avatar 370" in the spectral range $4000-250 \mathrm{~cm}^{-1}$ of the drug from $200 \mathrm{mg}$ to $10 \mathrm{mg}$ of CsI samples, used in the analysis of the prefix-Avatar diffuse reflectance. Gel was observed in the spectral range of $4000-400 \mathrm{~cm}^{-1}$ capillary layer in windows of KRS-5. The attachment used for the experiment was Transmission E.S.P.

\section{Results and Discussion}

It was found that X-ray diffraction patterns of samples of vanadium-containing gel, taken within the range from 5 to 25 minutes, are identical. X-ray diffractions show amorphous component of the gel which by heating the sample is retained, but the intensity of the corresponding peak in X-ray decreases.

On X-ray diffraction sample (Table 1), aged in the air for $5 \mathrm{~min}$, it is seen that the intensity of the amorphous component decreases by decaying into separate reflexes, and in a little corner area the intensity of a new phase begins to appear.

On the X-ray diffraction (Table 2) for gel dried in air for 30 minutes, vanadium hydroxide peaks (peaks numbers 4,5 ) appear [5]. New noncrystalline phases appear in the region of $6-8^{\circ}$ with decreased amorphous constituents.

In the process of gel aging in air for 40 minutes, there is a reduction in its water content, at the expense of evaporation and the resulting sample (Table 3 ); intensity redistribution in the diffraction maxima is observed on the XRD plot.

Due to the reduction of amorphous compounds, there is an increase in the intensity of the spacing boundaries plane in a small corner area of $5-12^{\circ}$. This dependence, as noted earlier, is, probably, due to the formation of $\mathrm{V}_{2} \mathrm{O}_{5} \cdot n \mathrm{H}_{2} \mathrm{O}$, as well as nonstoichiometric vanadium-containing compounds. There is also the appearance of diffraction lines corresponding to the emerging forms of vanadium oxides of $\mathrm{V}_{2} \mathrm{O}_{5}$ and $\mathrm{VO}_{2}$ in the $\mathrm{X}$-ray diffraction (Table 3 ) in a small region.

As a result of further removal of moisture, about $30 \%$ of vanadium hydroxide was present in the sample. Against this background, the crystallization and transition distribution of various forms of vanadium oxides occur and show the presence of $\mathrm{V}_{2} \mathrm{O}_{5} \cdot \mathrm{H}_{2} \mathrm{O}(30 \%), \mathrm{V}_{2} \mathrm{O}_{5}(13 \%), \mathrm{V}_{3} \mathrm{O}_{7}(45 \%)$, and $\mathrm{V}_{2} \mathrm{O}_{5}(11 \%)$ [5].

To observe dynamic changes of the curves, depending on the time of gel drying in air and accordingly the occurrence of phase components, collected X-ray diffractions have been superimposed on each other (Figure 1) and have been displayed in the 3D format. From the results obtained, one 
TABLE 2: X-ray diffraction of the gel dried in air for $30 \mathrm{~min}$.

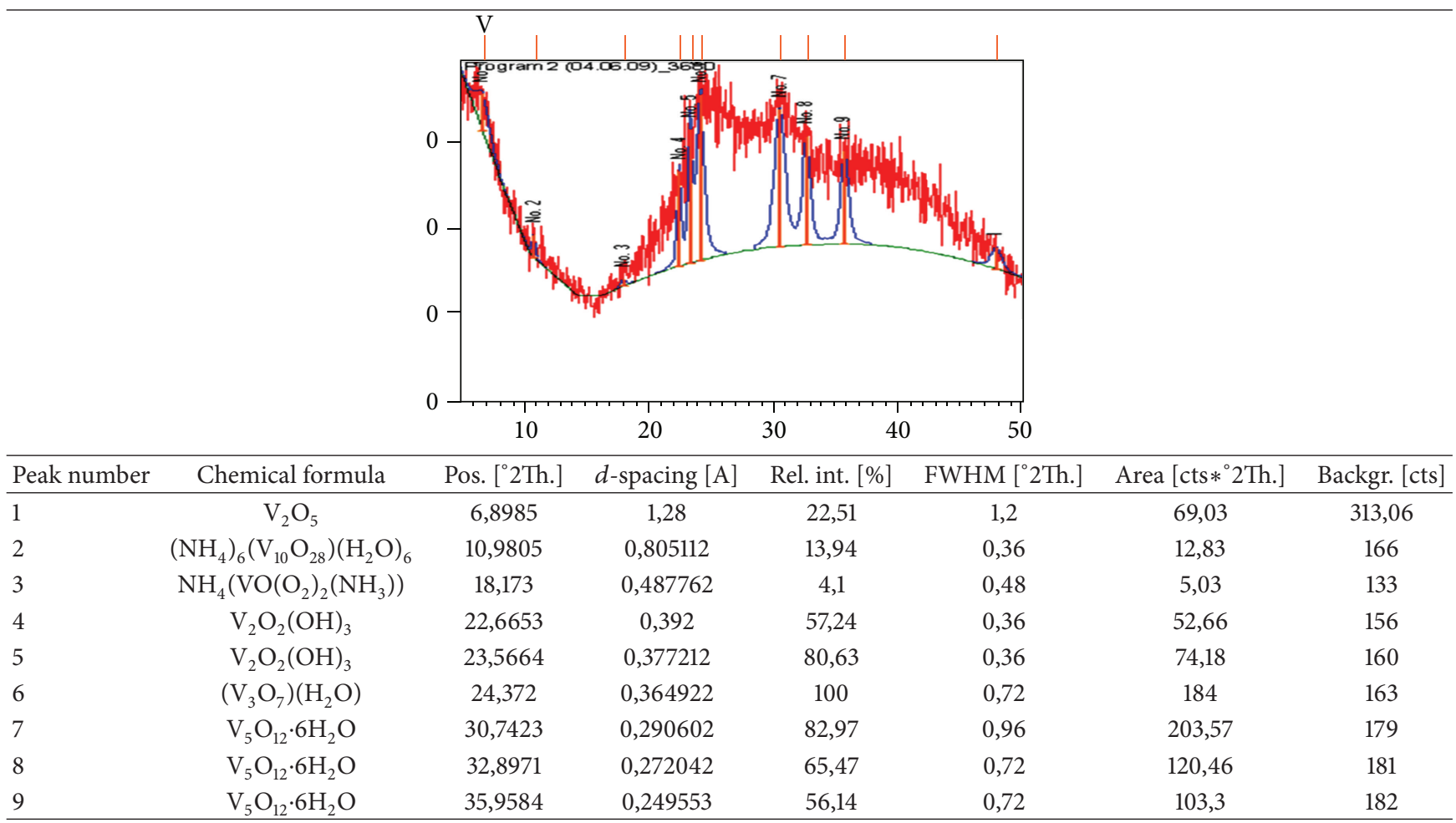

TABLE 3: X-ray diffraction of the gel dried in air for $40 \mathrm{~min}$.

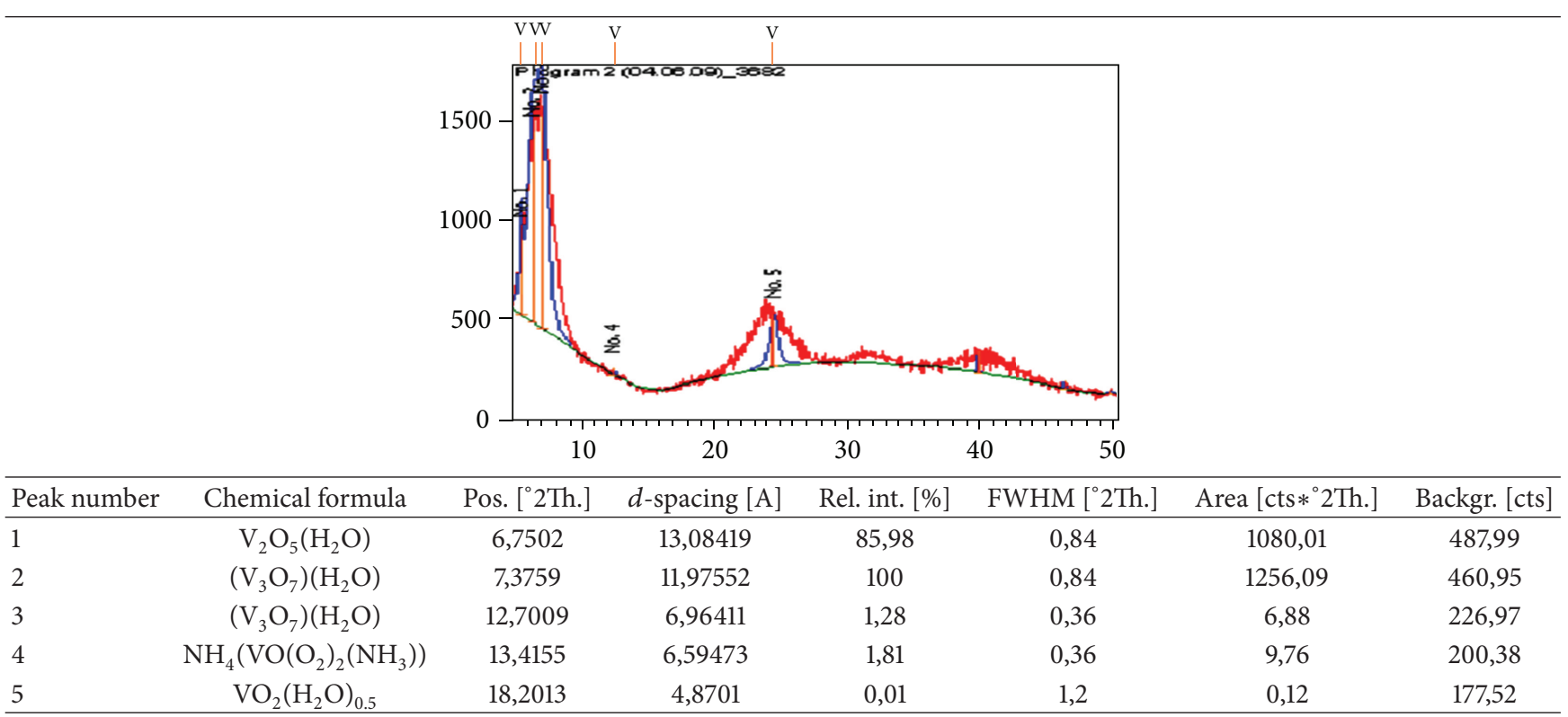

can see how the birth of the phases and their distribution occur as the water evaporates. The gel dries completely and uniformly; a transition linkage from crystallization water to $\mathrm{OH}$ groups occurs. Thus the composition of substance is changed, and the content of $\mathrm{V}_{2} \mathrm{O}_{5} \cdot\left(\mathrm{H}_{2} \mathrm{O}\right)$ is reduced from $30 \%$ to $8 \%$ [5].
In the process of sample drying, the layers of gel are depleted from water and phase transitions occur. As a result, the formation of a layered gel structure is observed. It is well observed on X-ray diffractions presented in Figure 2.

The results are in good agreement with the data of thermogravimetric studies. Isothermal effect corresponds to each 


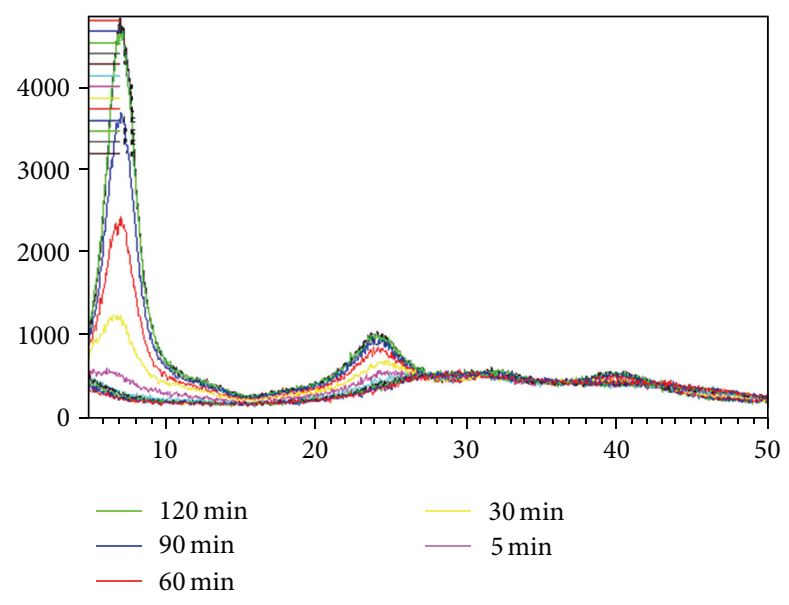

FIGURE 1: The results of superimposed X-ray diffraction of the gel vanadium as a function of aging time.

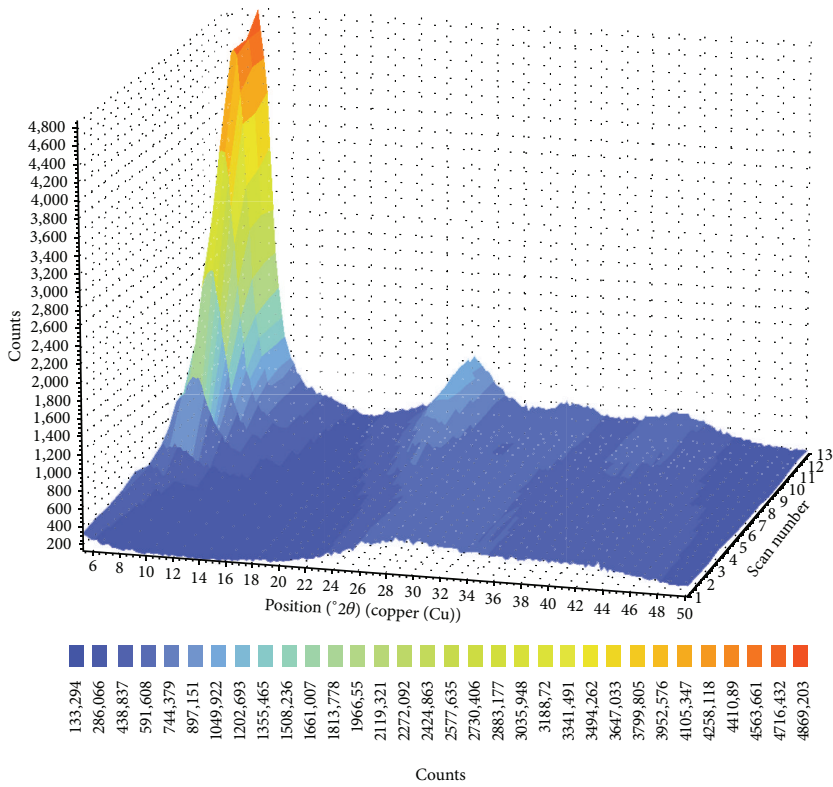

FIGURE 2: Topographical 3D presentation of X-ray diffraction plots during sequential removal of water from the xerogel.

stage at a constant temperature, as process of crystallization of compounds from amorphous component of the gel takes place. The fibers in the gel have some kind of a chaotic molecular structure which, with removal of water, leads to ordering.

On thermogram of the gel, vanadium-containing (Figure 3) endothermic peaks at 82.3, 140, 277.2, 355.9, and $382.6^{\circ} \mathrm{C}$ are fixed. Partially hygroscopic and partially waterincluding components of the crystalline hydrate and some oxide compounds are removed up to $300^{\circ} \mathrm{C}$. Communication between layers occurs by converting water of crystallization to $\mathrm{OH}$ groups. In addition, phase transitions occur at temperatures of 80,277 , and $355^{\circ} \mathrm{C}$ and are associated with the formation of $\mathrm{V}_{2} \mathrm{O}_{5} \cdot n \mathrm{H}_{2} \mathrm{O}$, as well as nonstoichiometric vanadium-containing compounds. The results of the first derivative differential thermal curve (DDTA) and X-ray analysis for measuring plane spacing and the process of crystallization of $\mathrm{V}_{2} \mathrm{O}_{5} \cdot n \mathrm{H}_{2} \mathrm{O}$ at $150^{\circ} \mathrm{C}$ are confirmed $[5,6]$.

The method of scanning probe microscopy (Figure 4 ) also confirmed the formation of the layered structure xerogel of vanadium, formed by conversion of fibers with $\mathrm{V}-\mathrm{O}$ chains and water molecules.

Absorption valence bands (Figure 5) of $v(\mathrm{OH})$, $3400 \mathrm{~cm}^{-1}$, deformational band of $\delta \mathrm{HOH}, 1651 \mathrm{~cm}^{-1}$, and liberational band of $v_{L} \mathrm{H}_{2} \mathrm{O}, 739 \mathrm{~cm}^{-1}$, fluctuations of molecular water were observed on the IR spectrum of the gel $[7,8]$. The absorption band with a maximum, at a wave number of $1013 \mathrm{~cm}^{-1}$, falls in the range of manifestations of the stretching vibrations of $\mathrm{V}=\mathrm{O}$ [8]. Stretching vibrations of $\mathrm{V}-\mathrm{O}$ at $747 \mathrm{~cm}^{-1}$ and of $\left[\mathrm{V}_{2} \mathrm{O}_{8}\right] 2-\infty-$ at $503 \mathrm{~cm}^{-1}$ were found. 


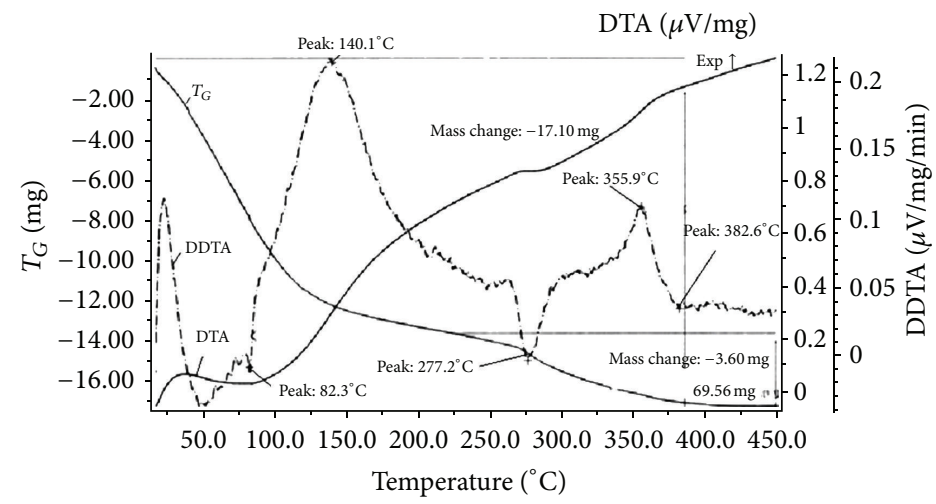

FIGURE 3: Thermogravimetric analysis of the vanadium-containing gel.

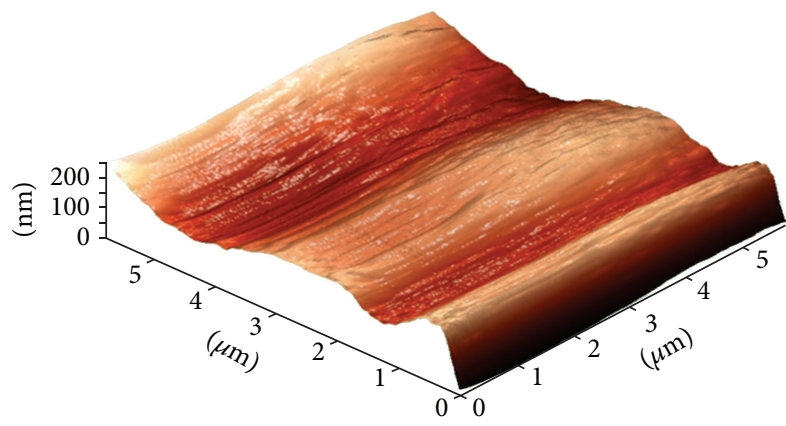

FIGURE 4: 3D image of the gel photographed on the probe microscope.

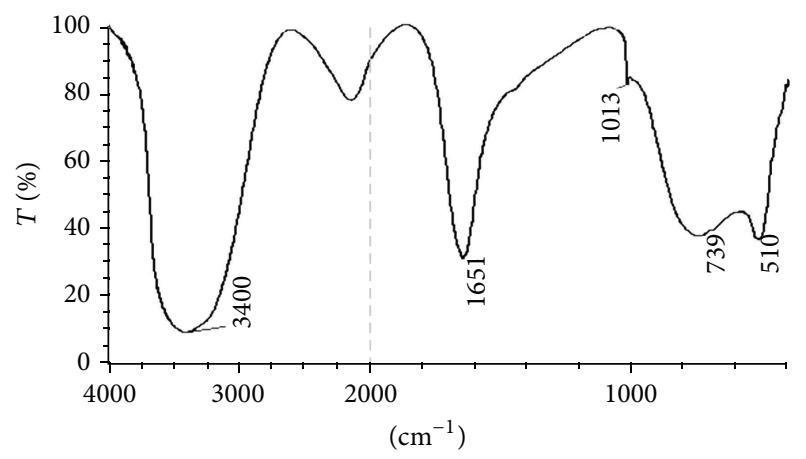

(a)

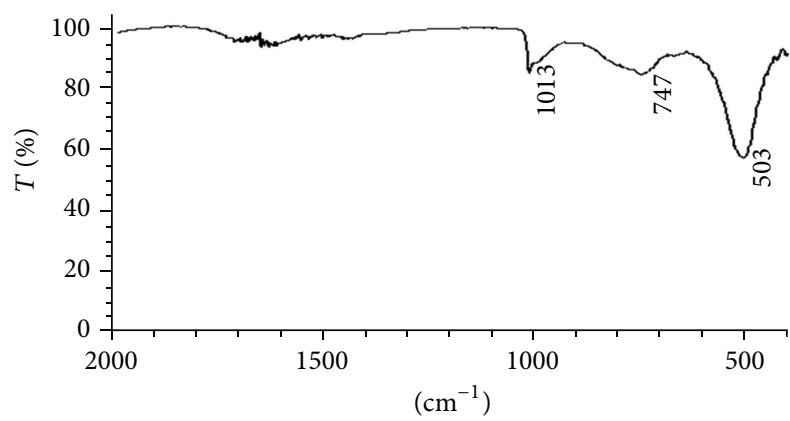

(b)

FIGURE 5: IR spectra of the vanadium xerogel. (a) IR spectrum of the gel; (b) IR spectrum of the gel with subtraction spectrum of water.
Fibers present themselves as flat ribbons of $100 \mathrm{~nm}$ length and width of $10 \mathrm{~nm}$, the structure of which corresponds to the orthorhombic structure of vanadium pentoxide of $\mathrm{V}_{2} \mathrm{O}_{5}$ $[9,10]$.

\section{Conclusion}

Synthesis of vanadium gel has been carried out using ammonia as the template and the study of its structure confirms the formation of porous layered surface of different compounds containing vanadium. Delaminated structural fibers with disordered muddled filamentous particles were obtained.

Highly anisotropic particles, similar in size to the "tapes" of vanadium oxide gel, were found on the surface of partially ordered layers. IR spectroscopic analyses of groups of $\mathrm{V}=\mathrm{O}$ and of $\mathrm{V}-\mathrm{O}$ bonds suggest that the high degree of order in the films is related to the fact that one of the water molecules is found to be short in double bonded $\mathrm{V}=\mathrm{O}$ [5].

The results of X-ray analysis additionally proved that the synthesized vanadium-containing gel is a nanoscale material.

Thus, in the process of removing moisture by air-drying of the synthesized vanadium-containing gel, transition linkages occur from water of crystallization to $\mathrm{OH}$ groups, thus forming the layered structure fibers of $\mathrm{VO}$ chains and water molecules. Orthorhombic crystal ribbons are not located in a common plane but form as a relief nanoscale structure.

\section{Conflict of Interests}

The authors declare that there is no conflict of interests regarding the publication of this paper.

\section{References}

[1] V. A. Kozlov, A. O. Baikonurova, S. B. Nurzhanova, M. S. Markametova, and V. N. Ermolaev, "Study of the structure of vanadium pentoxide gel X-ray diffraction method, Com," in Materials XIII International Baykonurov Readings at O.A. Baikonurov and Development of Modern Mining Science, Economics and Education of Kazakhstan, pp. 235-237, Zheskazgan, Kazakhstan, 2013. 
[2] G. S. Zakharova, V. L. Volkov, V. V. Ivanovskaya, and A. L. Ivanovskii, "Nanotubes and related nanostructures of d-metal oxides: synthesis and computer design," Uspekhi Khimii, vol. 74, no. 7, pp. 651-685, 2005.

[3] V. A. Kozlov, The Modern Theoretical Concepts of Chemistry of Vanadium in Aqueous Solutions, Inter-Press Publishers, Almaty, Kazakhstan, 2008.

[4] A. I. Maximov, V. A. Moshnikov, Y. M. Tahirov, and O. A. Shilov, Fundamentals of Sol-Gel Processing of Nanocomposites, Elmore, St. Petersburg, Russia, 2007.

[5] M. S. Markametova, Study of the synthesis conditions, the composition and structure of ammonia complex of vanadium [M.S. thesis], Kazakh National Technical University, Almaty, Kazakhstan, 2011.

[6] M. S. Markametova, A. O. Baikonurova, V. A. Kozlov, S. B. Nurzhanova, and V. Ermolaev, "Obtaining vanadium nanostructures by sol-gel process," Industry in Kazakhstan, vol. 3, no. 66, pp. 73-75, 2011.

[7] F. Krumeich, H. J. Muhr, M. Niederberge, F. Bieri, M. Reinoso, and R. Nesper, "The cross-sectional structure of vanadium oxide nanotubes studied by transmission electron microscopy and electron spectroscopic imaging," in Proceedings of the 2000 Materials Research Society Symposium, pp. 393-398, 2000.

[8] X. Chen, X. Sun, and Y. Li, "Self-assembling vanadium oxide nanotubes by organic molecular templates," Inorganic Chemistry, vol. 41, no. 17, pp. 4524-4530, 2002.

[9] A. V. Grigorieva and A. B. Tarasov, "Multi-walled nanotubes based on the oxides of titanium and vanadium as promising materials for hydrogen energy," in Proceedings of the 4th International Symposium on Hydrogen Energy of the Future and the Platinum Group Metals in the CIS, pp. 6-8, 2007.

[10] P. M. Ajayan, O. Stephan, P. Redlich, and C. Colliex, "Carbon nanotubes as removable templates for metal oxide nanocomposites and nanostructures," Nature, vol. 375 , no. 6532, pp. 564567, 1995. 

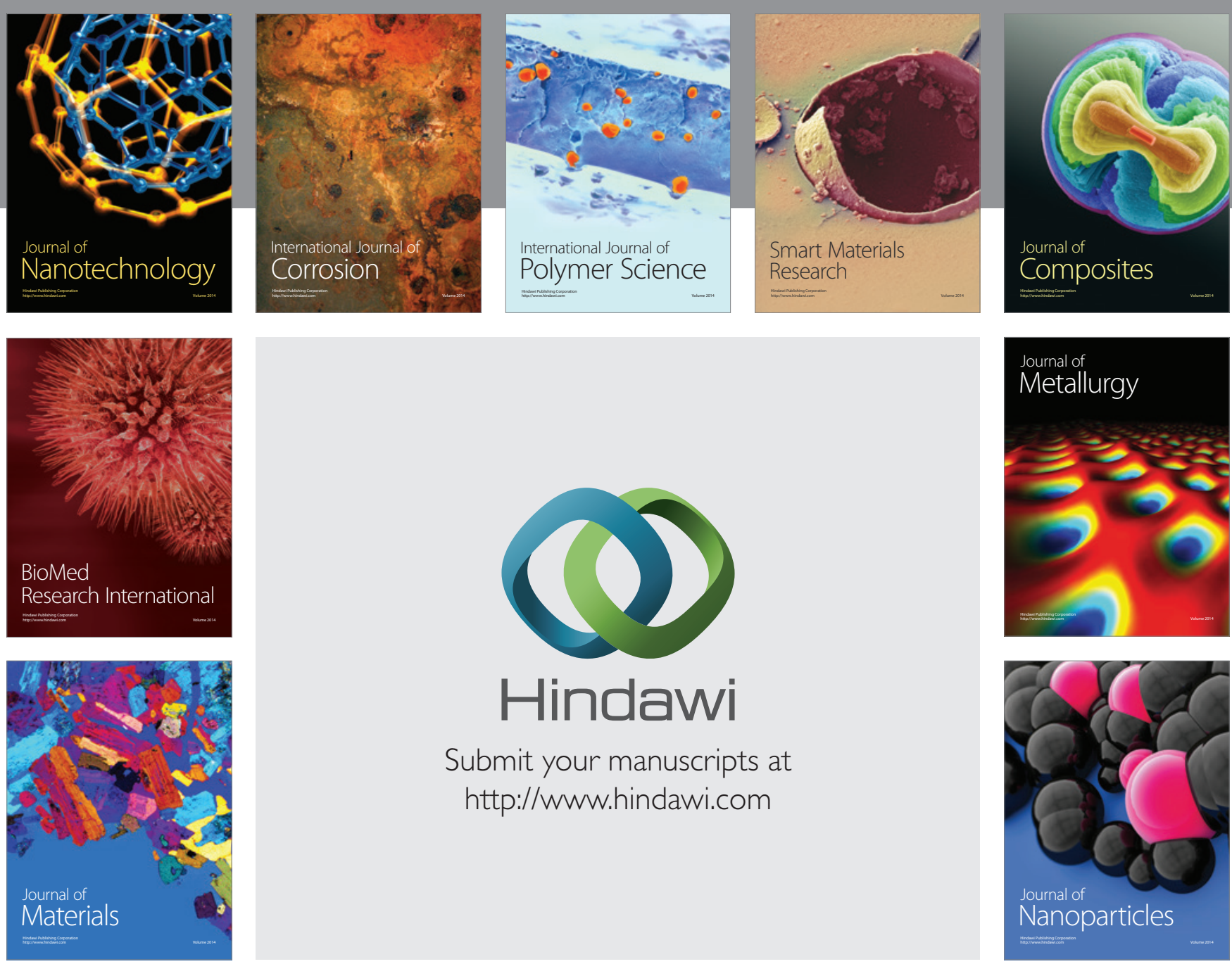

Submit your manuscripts at http://www.hindawi.com
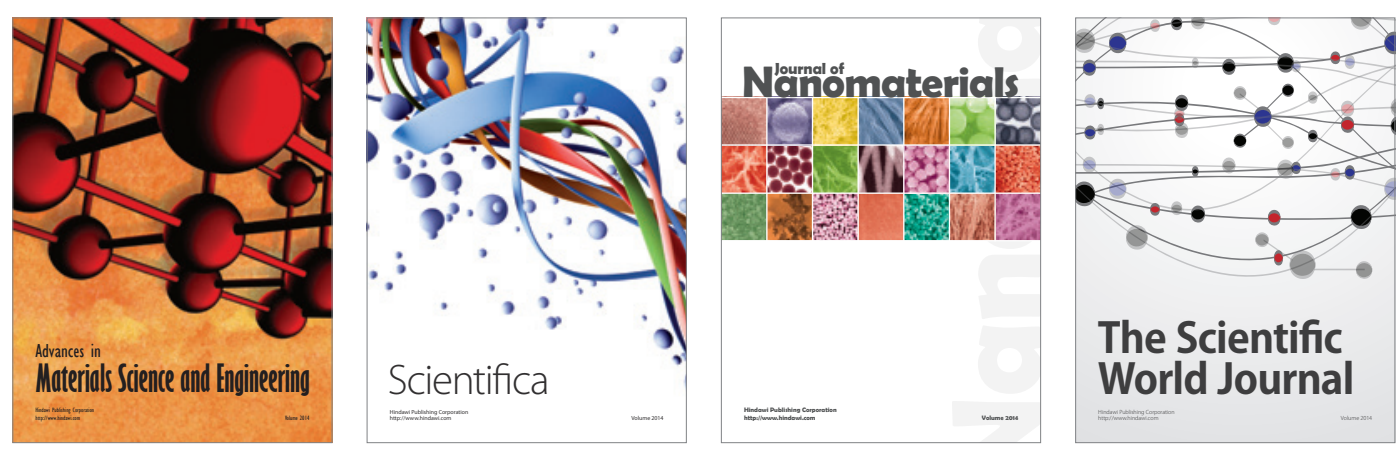

\section{The Scientific World Journal}
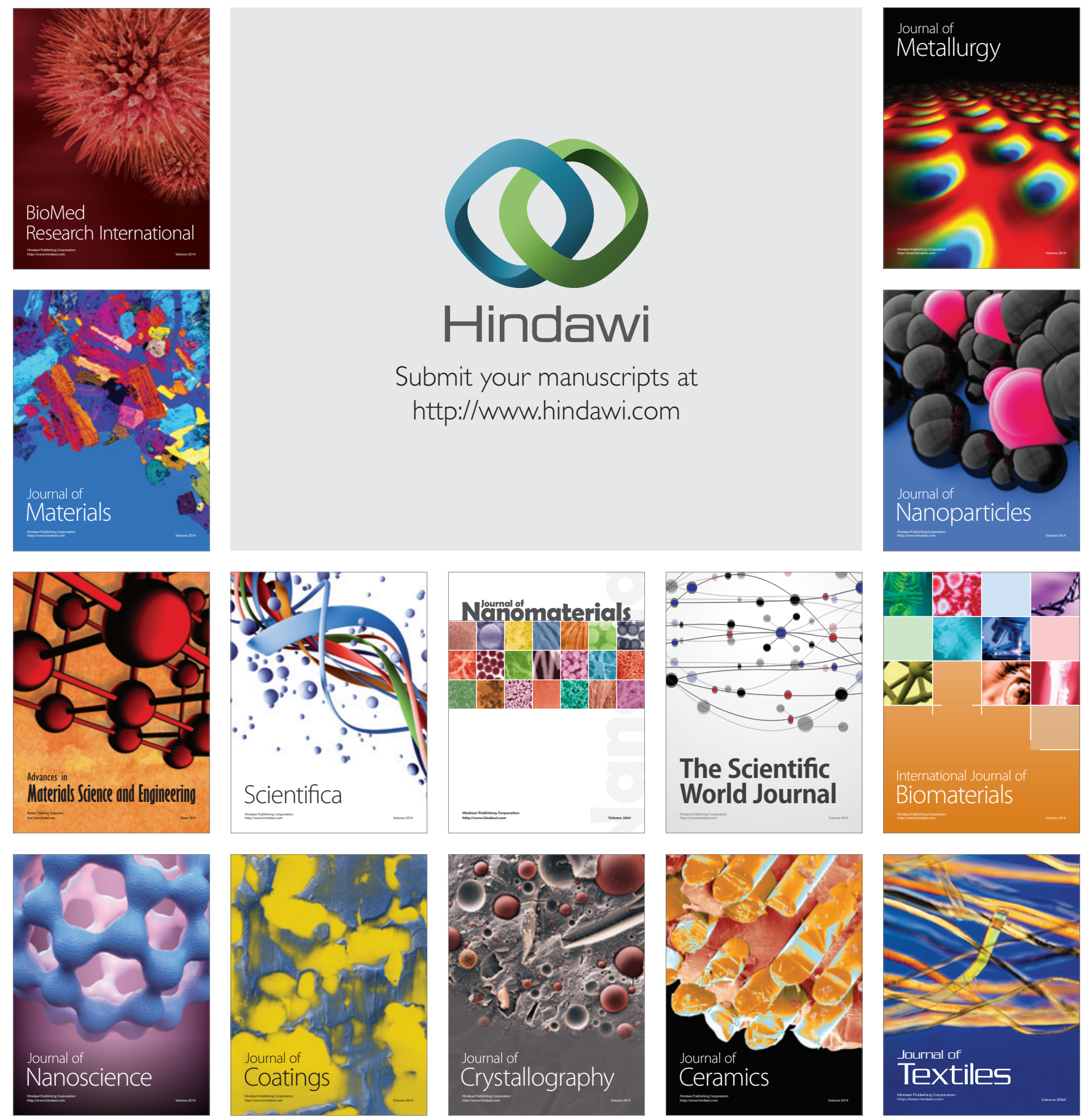